Оригинальные статьи / Original articles

https://doi.org/10.18619/2072-9146-2019-6-10-18 УДК 635.345:631.523:575.224.234

Козарь Е.В., Коротцева К.С. Романова О.В., Чичварина О.А., Кан Л.Ю., Ахраменко В.А. Домблидес Е.А.*

Федеральное государственное бюджетное научное учреждение

"Федеральный научный центр овощеводства" (ФГБНУ ФНЦО)

143072, Россия, Московская область,

Одинцовский район, п. ВНИИССОК,

ул. Селекционная, д. 14

^E-mail: Edomblides@mail.ru

Благодарность: Авторы выражают благодарность Артемьевой А.М. за предоставленный коллекционный материал капусты пурпурной (B.purpuria) и Скапцову М. за помощь в оценке растений-регенерантов методом проточной цитометрии клеточных ядер.

Конфликт интересов: Авторы заявляют об отсутствии конфликта интересов.

Для цитирования: Козарь Е.В., Коротцева К.С., Романова О.В., Чичварина О.А., Кан Л.Ю., Ахраменко В.А., Домблидес Е.А. Получение удвоенных гаплоидов Brassica purpuraria. Овощи России. 2019;(6):10-18

https://doi.org/10.18619/2072-9146-2019-6-10-18

Поступила в редакцию: 03.11.2019

Принята к печати: 18.11.2019

Опубликована: 25.11.2019

Elena V. Kozar, Ksenia S. Korottseva, Olga V. Romanova, Olga A. Chichvarina, Lyudmila Yu. Kan,

Vladislav A. Ahramenko,

Elena A. Domblides*

Federal State Budgetary Scientific Institution

Federal Scientific Vegetable Center (FSBSI FSVC)

14 , Selectsionnaya str., VNIISSOK, Odintsovo dis-

trict, Moscow region, Russia, 143072

*E-mail: Edomblides@mail.ru

Acknowledgment: The authors express special acknowledgement to Anna M. Artemyeva for the collection material of purple cabbage (B.purpuria) and Mikhail Skaptsov for his help in assessing regenerated plants by flow method cytometry of cell nuclei.

Conflict of interest: The authors declare no conflict of interest.

For citation: Kozar E.V., Korottseva K.S Romanova O.V., Chichvarina O.A., Kan L.Yu., Ahramenko V.A., Domblides E.A. Production of doubled haplois in Brassica purpuraria. Vegetable crops of Russia. 2019;(6):10-18. (In Russ.) https://doi.org/10.18619/2072-9146-2019-6-10-18
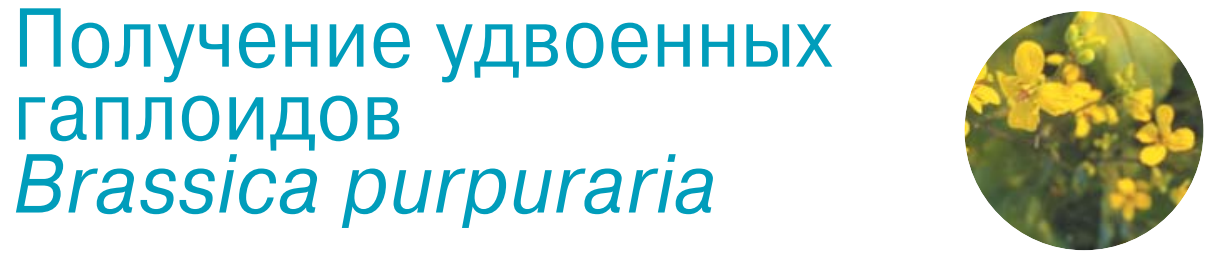

PEЗЮME

Актуальность. Овощная культура Brassica rapa L. ssp. chinensis (L.) Hanelt var. purpuraria (L.H. Bailey) Hanelt (синонимы: Brassica campestris L. var. purpurea Bailey; Brassica rapa L. ssp. chinensis var. purpurea) в последние годы набирает популярность как объект генетико-молекулярных исследований и как овощное растение ввиду высокого содержания биологически активных веществ и хозяйственно ценных признаков. Эффективной технологии получения DH-растений для ускорения селекционного процесса у этой культуры еще не разработано, поэтому исследования в этой области актуальны.

Материалы и методы. В исследование включены два сортообразца из коллекции ФГБНУ "Федеральный исследовательский центр Всероссийский институт генетических ресурсов растений имени Н.И. Вавилова" (ВИР): №1301(Китай) и №1357(Нидерланды). В ходе экспериментов использовали стандартный протокол получения DH-растений в культуре изолированных микроспор in vitro и протокол с добавлением нитрата серебра $\left(\mathrm{AgNO}_{3}\right)$ в питательную среду для стимулирования индукции эмбриогенеза. Для определения плоидности растений-регенерантов использовали прямой подсчет хромосом в меристемных клетках и метод проточной цитометрии клеточных ядер.

Результаты. В результате исследования установлено, что эмбриогенез в культуре В. purpuraria возможен как при использовании стандартного протокола, так и с добавлением нитрата серебра, который положительно влияет на индукцию эмбриогенеза. Выход эмбриоидов варьировал в зависимости от генотипа индивидуального растения в пределах сортообразца. Максимальный выход эмбриоидов составил 40 эмбриоидов на чашку Петри. Обозначена основная проблема, возникающая на этапе регенерации: около половины растений-регенерантов оказались альбиносами и были нежизнеспособны. Показана высокая степень спонтанного удвоения хромосом в растениях-регенерантах. Всего было получено 38 растений-регенератов из сортообразца №1301. Выявлено, что у некоторых DH-растений при инбридинге проявляется самонесовместимость (4 шт), в то время как у остальных растений семенное потомство было получено. Созданный материал передан для генетических исследований и селекционной работы. Ключевые слова: Brassica rapa ssp. chinensis var. purpuraria, культура изолированных микроспор, удвоенные гаплоиды, андрогенез, регенерация растений, проточная цитометрия.

\section{Production of doubled haplois in Brassica purpuraria}

\section{ABSTRACT}

Relevance. In recent years vegetable crop Brassica rapa ssp. chinensis var. purpuraria (synonyms: Brassica campestris L. var.purpurea Bailey; Brassica rapa L. ssp. chinensis var. purpurea) is gaining popularity as an object of genetic and molecular researches, and as an economically valuable vegetable plant due to the high content of biologically active compounds and distinctive economically valuable traits. Effective technology for development DH-plants to accelerate the breeding process for this culture has not been developed yet, so research in this area is relevant.

Materials and methods. The study included two varieties from the collection of Vavilov AllRussian Research Institute of Plant Industry (VIR): No. 1301 (China) and No. 1357(Netherlands). Both protocols standard unmodified and with addition of silver nitrate $\left(\mathrm{AgNO}_{3}\right)$ in the medium for embryogenesis induction were used in experiments for production of DH plants from isolated microspore in vitro. Direct chromosome counting in meristem cells and flow cytometry were used to determine the ploidy of regenerating plants.

Results. As a result of the study embryogenesis in $B$. purpuraria culture can develop with the use of a standard protocol as well as with the addition of silver nitrate that showed a positive effect on the induction of embryogenesis. The yield of embryoids varied depending on the genotype of the individual plant within the variety accession. The highest yield of embryoids was 40 embryoids/petri dish. The main problem at the stage of regeneration is that about half of the regenerating plants occurred to be albinos and were not viable. We show a high degree of spontaneous chromosome doubling in regenerated plants (all analyzed plants were doubled haploids). In total 38 regenerated plants were obtained from accession No. 1301. It was shown that four DH-plants had self-incompatibility after self-pollination, but seed progeny from other plants was obtained. The created material was taken for genetics study and breeding work.

Keywords: Brassica rapa ssp. chinensis var. purpuraria, isolated microspore culture, doubled haploids, androgenesis, plant regeneration, flow cytometry. 


\section{Введение}

вощное растение Brassica rapa L. ssp. chinensis (L.) Hanelt var. purpuraria (L.H. Bailey) Hanelt (синонимы: Brassica rapa ssp. chinensis (Bailey) Hanelt var. purpuraria Kitam; Brassica campestris L. var. purpurea Bailey; Brassica rapa L. ssp. chinensis var. purpurea) не образует кочана и съедобной его частью являются красный стебель и листья. Выращивают B.purpuraria в осенне-зимний период в Центральном Китае вдоль долины реки Янцзы, в России мало распространена. В Китае эта культура получила названия Purple cai-tai и Zicaitai. В России она пока мало распространена и называется капуста пурпурная.

Благодаря высокому содержанию уникальных биологически активных соединений в съедобных стеблях и листьях пурпурная капуста пользуется спросом в странах Азии, Европы и Америки (Li et al., 2019). В последние годы эта культура стала востребованным объектом для молекулярных и генетических исследований.

Одними из биологически активных веществ, представляющих интерес и входящих в состав B. purpuraria, как и во многих других растениях семейства Brassicaceae, являются глюкозинолаты. Продукты их распада проявляют биологически активные функции в растениях, такие как регуляция ростовых процессов в клетках и защитные функции при поражениях различными патогенами (Козарь Е.Г., 2011 2017). При потреблении в пищу продукты распада глюкозинолатов в соответствующих концентрациях проявляют антибактериальную, противораковую, радиосенсибилизирующую активности, выводят из клеток организма канцерогены активизируют ферменты печени, способствуют нормальному функционированию эндокринной системы (Chen et al., 2008). Глюкозинолаты придают крестоцветным овощам характерный запах и горьковатый острый вкус.

Другими активными веществами, представляющими интерес, являются антоцианы. За счет широкого спектра их фармакологического действия эти соединения часто входят в состав биологически активных пищевых добавок. Антоцианы снижают воспалительные реакции, окислительный стресс в кишечнике и повышают его барьерные функции, являются профилактическим средством от онкологических заболеваний и болезней сердца. Изучению генов, контролирующих накопление антоцианов в растениях и определяющих пурпурную окраску, уделяется большое внимание. Такие исследования начаты и в отношении культуры B. purpuraria (Guo et al., 2015). Ведутся работы по созданию генетической карты для идентификации локусов контролирующих накопление антоциана в стебле растения (Li et al., 2019).

Также B. purpuraria интересна наличием ценного сельскохозяйственного признака - глянцевой поверхности листа без воскового налета. Эта фенотипическая особенность интересна для повышения товарного качества культурных растений, в связи с чем проводятся исследования по выявлению отвечающих за нее генов (Wang et al., 2019).

Для проведения молекулярных и генетических исследований лучшим материалом являются растения, которые гомозиготны по изучаемым признакам. Без таких растений не обходится и любой процесс создания новых и совершенствования имеющихся сортов и гибридов, поэтому получение DH-растений крайне важно и востребовано. Капуста пурпурная является перекрестноопыляемой культурой, поэтому создание чистых линий традиционным способом (инбридинг) требует больших временных и трудовых затрат. Применение биотехнологических методов позволяет не только существенно сократить время получения гомозиготных растений, но и выявлять полезные гены, особенно редких рецессивных признаков и создавать уникальные формы, повышая эффективность практической селекции (Maluszynski et al., 2003; Dunwell, 2010; Asif, 2013)
Культура изолированных микроспор in vitro является одним из передовых методов получения DH-растений, основанных на клеточных технологиях (Ferrie et al., 2011). Однако для применения этого метода в практической селекции необходима его высокая эффективность, которая обусловлена большим числом факторов, часто обладающих высокой сорто- и генотип-специфичностью, что осложняет процесс разработки методики для разных культур.

Для некоторых культур семейства Brassicaceae технология получения удвоенных гаплоидов уже разработана и применяется в практической селекции, однако некоторые другие растения этого семейства, в том числе, В. purpuraria, проявляют низкую отзывчивость к эмбриогенезу, и пока не удалось получить достаточный выход эмбриоидов для использования DH-технологии в селекционном процессе, поэтому необходима дальнейшая разработка и совершенствование этого метода (Ferrie, 2003, Козарь Е.В., 2018). На настоящий момент в литературе опубликованы результаты двух исследований китайских ученых, посвященных получению DH-растений B. purpuraria в культуре микроспор in vitro. В одном из исследований микроспоры в дополнение к стандартному протоколу подвергали тепловому шоку $32^{\circ} \mathrm{C}$ с экспозицией от 12 до 72 часов и культивировали на средах NLN-13 и 1/2 NLN-13. Лучшие результаты показал температурный шок длительностью 18 часов, совместно с половинной средой для индукции эмбриогенеза. Максимальный выход эмбриоидов у наиболее отзывчивого генотипа пурпурной капусты китайской составил 70,5 эмбриоидов на чашку Петри (Wang et al., 2009). В другом исследовании стандартный протокол был дополнен введением в индукционную среду NLN-13 поверхностно активных веществ, которые повышали индукцию эмбриогенеза, тем не менее, выход эмбриодов был низким и не превышал 13,5 эмбриоидов на бутон для самого отзывчивого генотипа (Gao et al, 2019).

Выход DH-растений зависит не только от эффективности эмбриогенеза и количественного выхода эмбриоидов, но и от этапов регенерации, укоренения, а также степени полиплоидизации растений-регенерантов, поскольку растения, находящиеся в гаплоидной форме, не способны завязывать семена и не пригодны для создания чистых линий в селекции.

На эффективность индукции эмбриогенеза влияет множество факторов, одним из них является выделение этилена при культивировании микроспор, так как в больших концентрациях он может оказывать токсическое действие и препятствовать нормальному развитию эмбриоидов. Нитрат серебра - одно из веществ, которое эффективно ингибирует этилен. В литературе встречаются исследования по влиянию добавления нитрата серебра в питательную среду на выход эмбриоидов в культуре микроспор in vitro у различных представителей Brassica. Сообщалось о положительном действии $\mathrm{AgNO}_{3}$ на выход эмбриоидов в культуре микроспор брокколи (B. oleracea L. var. italica Plenck). Нитрат серебра в концентрации 0,1 мг/л повышал выход эмбриоидов более чем в 2 раза (Na et al., 2011). Аналогичные результаты получены в исследовании по влиянию $\mathrm{AgNO}_{3}$ на выход эмбриоидов B. rapa ssp. - концентрация 0,1 мг/л была наиболее эффективной и повышала выход эмбриоидов на 27-36\% в зависимости от генотипа (Kabir et al., 2013). Однако некоторые ученые считают, что повышение эмбриогенеза при добавлении в среду нитрата серебра является генотип-зависимой реакцией (Wang et al. 2004). То же отметили Biddington с соавт., из трёх отзывчивых генотипов, только для одного добавление нитрата серебра повысило выход эмбриоидов (Biddington et al., 1988).

На этапе регенерации эмбриоидов, полученных в культуре микроспор in vitro, может возникнуть проблема альбинизма, 
как и в других клеточных технологиях получения DH-растений. Альбинизм характеризуется частичной или полной потерей хлорофилловых пигментов и неполной дифференцировкой мембран хлоропластов. Это, в свою очередь, ухудшает фотосинтез, и растения, в конечном итоге, погибают на начальных стадиях, не достигая зрелости (Smith, 1999). Об альбинизме сообщали при экспериментальном андрогенезе в культуре in vitro у многих видов растений, таких как ячмень, пшеница, арахис, соя, нут, фасоль, арабидопсис, табак, томат, понтедерия, белая сосна и морковь столовая (Jahne and Lorz, 1995; Caredda and Clement, 1999; Вюртц Т.С., 2017). Для растений рода Brassica проблема мутаций окраски листьев также является значимой. Цитологические, физиологические и протеомные исследования мутаций окраски листьев были опубликованы для B. napus (Chu et al., 2014).

На частоту образования растений-альбиносов могут влиять условия окружающей среды, такие как свет, температура, состав питательных сред и условия культивирования Определяющими факторами являются генотип и физиологическое состояние донорных растений (Moieni and Sarrafi, 1995), температура, при которой происходит культивирование (Huang, 1984), предварительная холодовая обработка (Genovesi and Magill, 1979), концентрация сахарозы в сочетании с гормонами роста (Clapham, 1973), стадия развития микроспор (Chen and Lin, 1976) и длительность культивирования эмбриоидов (Haliloglu and Baenziger, 2003).

Большинство исследований наследственности альбинизма показали, что это рецессивный признак, управляемый одним или двумя генами с двумя аллелями, что объясняет частоту образования растений-альбиносов в клеточных технологиях получения DH-растений. Поэтому альбинизм является серьезной проблемой в культуре микроспор in vitro. Например, у некоторых генотипов пшеницы и ячменя в культуре пыльников было получено до 100\% растений-альбиносов (Knudson et al., 1989; Jahne et al., 1991). Однако в исследовании Wang с соавторами (2016) отмечено, что признак желтоватых листьев у Brassica napus контролируется одним доминантным геном, что предполагает еще большую вероятность проявления данного признака, причем не только в гомозиготных растениях.

Цель исследований - получение DH-растений в культуре B. purpuraria для включения полученного линейного материала в селекционный процесс и для генетических исследований.

\section{Материал и методь}

В работе использовали сортообразцы В. purpuraria из коллекции ФГБНУ «Федеральный исследовательский центр Всероссийский институт генетических ресурсов растений имени Н.И. Вавилова» (ВИР) (табл.1).

Донорные растения для каждого сортообразца были высажены в количестве пяти растений, которые выращивали в климатической камере при температуре $21^{\circ} \mathrm{C}$ и фотопериоде 16 часов с лампами досвечивания (Osram plantstar 600w) освещенностью 9000 люкс.

Исследование стадий развития микроспор. Для определения взаимосвязи между размером бутона и стадией

Таблица 1. Список сортообразцов

B. purpuraria, включенных в исследование.

Table 1. List of varieties of B. purpuraria included in the study
№ п. п.

№ в каталоге ВИР

2 вp. 1301

Китай развития микроспор проводили цитологические исследования. Для визуализации стадии развития микроспор использовали методику дифференциального окрашивания (Alexander, 1969) и микроскоп Aхіо Imager A2 (Carl Zeiss, Германия). С помощью препаровальных игл микроспоры выделяли из бутонов на предметное стекло, добавляли каплю красителя, накрывали покровным стеклом и изучали при 200 и 400-кратном увеличении. Суспензию микроспор просматривали из бутонов различной длины от 1,8 до 4,8 мм. С помощью этого метода, также определяли фертильность микроспор и пыльцы.

Исследование влияния нитрата серебра $\left(\mathrm{AgNO}_{3}\right)$ в составе индукционной питательной среды на эффективность эмбриогенеза проводилось в трёх повторностях. Для данного опыта была взята концентрация нитрата серебра - 0,1 мг/л (оптимальная по литературным данным для Brassica rapa), контроль - чашки Петри без добавления $\mathrm{AgNO}_{3}$.

Индукция эмбриогенеза в культуре микроспор. В основе опытов применяли базовую методику, разработанную в лаборатории биотехнологии (ФГБНУ ФНЦО) для культуры микроспор семейства Brassiaceae (Домблидес и др., 2016). В качестве питательной среды использовали среду NLN-13 (Lichter, 1982), после введения в культуру микроспор in vitro проводили температурную обработку в термостате при $32^{\circ} \mathrm{C}$. Для опытов использовали реактивы компании SIGMA с маркировкой "plant cell culture tested".

Регенерация. Эмбриоиды на сердечковидной и торпедовидной стадиях помещали на среду MC (Murashige, Skoog, 1962), pH 5,8 с 2\% сахарозы, 7 г/л агара с добавлением регуляторов роста ГК 0,1 мг/л и БАП 1 мг/л. Образовавшиеся побеги и вторичные эмбриоиды отделяли и переносили на безгормональную среду $\mathrm{MC}$, pH 5,8 с 2\% сахарозы и 7 г/л агара для укоренения. Культивирование проводили на стеллажах с люминесцентными лампами, с фотопериодом 16 часов, освещенностью 3500 люкс, при постоянной температуре $23^{\circ} \mathrm{C}$.

Адаптация и выращивание растений-регенерантов. Растения с нормально развитыми листовой и корневой системами переносили в горшки, заполненные смесью торфа и перлита (7:3), накрывали перфорированными пластиковыми стаканчиками для поддержания высокой влажности и адаптации растений к условиям in vivo. Условия выращивания растений-регенерантов в климатической камере совпадали с условиями выращивания донорных растений

Определение плоидности производили прямым подсчетом числа хромосом (1) и с помощью проточной цитометрии клеточных ядер (2).

1. Цитологическое исследование осуществляли модифицированным пропионо-лакмоидным методом (Домблидес и др., 2016) путем приготовления давленых препаратов меристемы стебля и кончиков корней растений, корешков проростков. Препараты просматривали с помощью микроскопа Zeiss Scope.A1, оснащенного камерой Digital Camera Power Shot G10 Canon. Обработку изображений проводили с помощью программы Axio Vision, версия 4.8 (Carl Zeiss Microlmaging, Jena, Germany).

2. Проточную цитометрию клеточных ядер выполняли на базе лаборатории биоинженерии Алтайского Государственного Университета.

Относительное содержание ДНК определяли при помощи техник проточной цитометрии с использование иодида пропидия. Для исследования использовали свежие молодые листья растений-регенерантов, полученных в культуре in vitro. Листья измельчали при помощи лезвия в 1 мл Tris-MgCl буфера (Phosser et al., 1995) с изменениями следующего состава: 0,2 M Tris основание, 4 мM MgCl $2,0,5$ \% Triton X-100, 50 мкг/мл РНКазы, 0,5\% поливинилпирролидон К15, 50 мкг/мл иодида пропидия, pH 7,5). Данные флюоресценции 
изолированных ядер детектировали при помощи проточного цитометра Partec CyFlow PA (Partec, GmbH) с лазерным источником излучения С длиной волны 532 нм. Визуализацию и обработку гистограмм проводили с использованием программы Flowing Software 2.5.1. (University of Turku, Finland). Статистические данные рассчитывали в программе XLStat (Addinsoft). В качестве внутреннего стандарта для определения содержания ДНК внешних стандартов (образцов с известной плоидностью используемых в качестве внешних стандартов, т.е. исследуемых отдельно друг от друга без изменения настроек прибора) использовали Ficus benjamina (2C = 1,07 пг) (Скапцов и др., 2016), так как содержание ДНК было сопоставимо.

Содержание ДНК диплоидных стандартов (2С, пг) рассчитывали по формуле:

2C, пг = (Среднее пика Образца / Среднее пика Ficus benjamina) * 2C Ficus benjamina

Для определения плоидности и содержания ДНК в качестве внешнего стандарта использовали диплоидные образцы.
Плоидность определяли по индексу разницы между пиками диплоидного стандарта того же вида и образца:

Индекс = Среднее пика Образца / Среднее пика Стандарта

Содержание ДНК (2С, пг) рассчитывали по формуле:

2C, пг = (Среднее пика Образца / Среднее пика Стандарта) * 2С Стандарта

Статистический анализ был проведен с помощью пакета программ Microsoft Excel.

\section{Результаты}

Донорные растения двух сортообразцов, высаженные в климатической камере, развивались с разной скоростью и отличались по мощности, началу стеблевания и степени фертильности пыльцы. Для опытов было отобрано два растения сортообразца №1301 (Китай) с наиболее мощным габитусом, они обладали схожей фертильностью пыльцы, в среднем 87-91\%, но отличались по мощности и началу цветения (более мощное растение (далее - растение №1) (рис.1А) зацвело раньше, чем растение №2).
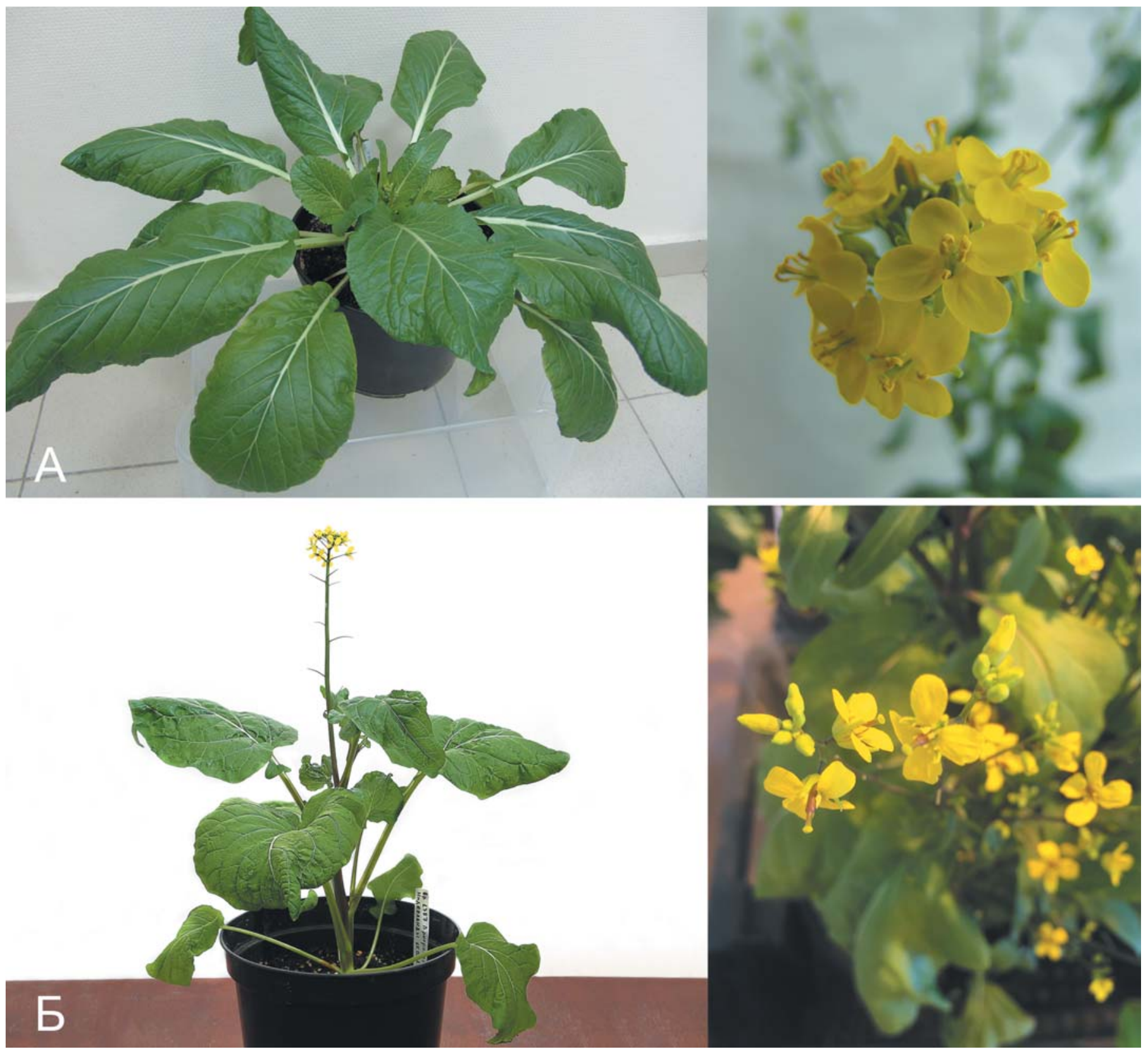

Рис. 1. Донорные растения В. purpuraria и их соцветия: А - сортообразец №1301(Китай), Б - сортообразец №1357(Нидерланды)

Fig. 1. Donor plants of B. purpuraria and their inflorescence: A - variety No. 1301 (China), Б -variety No. 1357(Netherlands) 
Таблица 2. Процентное соотношение фертильных микроспор B. purpuraria и пыльцы в зависимости от размера бутонов и растений сортообразца №1357

Table 2. Percentage of fertile microspores of

B. purpuraria and pollen depending on the size of buds and plants of variety No. 1357

\begin{tabular}{|c|c|c|}
\hline \multirow{2}{*}{ № растения } & \multicolumn{2}{|c|}{ \% фертильных микроспор и пыльцы } \\
\hline & 2,5-3,2 мм & 3,3-4,0 мм \\
\hline 1 & 0 & 0 \\
\hline 2 & 0 & 0 \\
\hline 3 & 0 & 0 \\
\hline 4 & $25 \pm 6$ & $24 \pm 9,2$ \\
\hline 5 & $12 \pm 4,4$ & $9 \pm 3,2$ \\
\hline
\end{tabular}

у сортообразца №1357 (Нидерланды) пыльники были слабо развиты, три растения были полностью стерильны, а два обладали пониженной фертильностью пыльцы (табл. 2). Для культивирования было отобрано одно растение (растение №4) с наиболее высокой фертильностью (рис.1Б).

Для успешного получения эмбриоидов крайне важна стадия развития микроспор. Показано, что микроспоры на поздней вакуолизированной одноклеточной и ранней двухклеточной стадиях развития способны менять путь развития с гаметофитного на спорофитный, благодаря чему в дальнейшем формируются эмбриоиды (Pechan, Keller, 1988). Такие стадии необходимо максимизировать в культуре, для чего требуется определить линейный размер бутонов, содержащих восприимчивые микроспоры в наибольшем количестве. По результатам предварительного цитологического исследования для введения в культуру микроспор in vitro у обоих сортообразцов было отобрано два диапазона линейных размеров бутона: 2,5-3,2 и 3,3-4,0 мм (табл.3).

Микроспоры из отобранных бутонов культивировали на среде NLN-13 по стандартному протоколу. Первые деления в культуре наблюдали на 2-3 сутки, формирование эмбриоидов происходило с суспензором и без. На 14-16 сутки эмбриоиды достигали глобулярной стадии развития, а на 1824 сутки - торпедовидной стадии (рис. 2).

У растения №1 выход эмбриоидов из бутонов размером 2,5-3,2 мм составил 20-40 эмбриоидов на чашку Петри (рис. 3А) и 2-3 эмбриоида на чашку Петри - из растения №2 Выход эмбриоидов из бутонов 3,3-4,0 мм у растения №1 составил 1-2 эмбриоида на чашку Петри (рис. ЗБ), а у растения №2 получить эибриоиды из бутонов такого размера не удалось. При культивировании растения сортообразца №1357 (Нидерланды) с пониженной фертильностью положительных результатов не получено, эмбриоиды не были сформированы, хотя деления клеток в культуре наблюдались в

Таблица 3. Зависимость между длиной бутонов В. purpuraria и содержанием в них восприимчивых микроспор (указан процент микроспор на поздней вакуолизированной стадии и пыльцы на ранней двухклеточной стадии развития от общего количества фертильных)

Table 3. The dependence between the length of buds of B. purpuraria and the content of susceptible microspores in them (the percentage of microspores in the late vacuolated stage and pollen at early binucleate stage from the total number of fertile)

\begin{tabular}{|c|c|c|c|c|}
\hline \multirow{2}{*}{ Сортообразец } & \multicolumn{4}{|c|}{ размер бутонов } \\
\cline { 2 - 5 } & $1,8-2,5$ мм & $\mathbf{2 , 5 - 3 , 2}$ мм & $\mathbf{3 , 3 - 4 , 0}$ мм & $4,1-4,8$ мм \\
\hline №1301 & $41 \pm 3,2$ & $\mathbf{5 9} \pm \mathbf{7 , 2}$ & $\mathbf{5 8} \pm \mathbf{6 , 4}$ & $37 \pm 4,4$ \\
\hline №1357 & $36 \pm 5,2$ & $\mathbf{4 9 \pm 5 , 2}$ & $\mathbf{4 6} \pm \mathbf{7 , 2}$ & $33 \pm 8,4$ \\
\hline
\end{tabular}
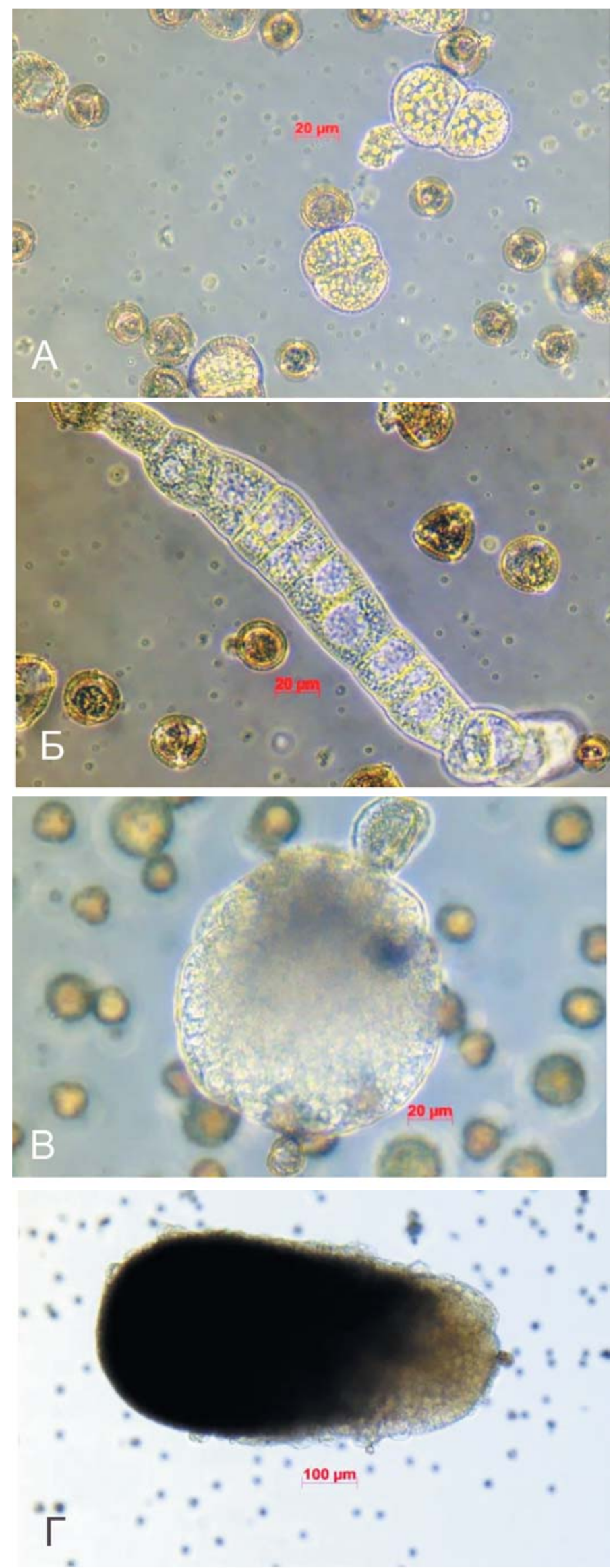

Рис. 2. Формирование эмбриоидов В. purpuraria: A - деления на 2-4 клетки (2-3 день культивирования); Б - эмбриогенная структура с суспензором (7 сутки культивирования); В - глобулярная стадия развития эмбриоида (15 сутки); I - торпебулярная стадия развития эмбриоида (15 сутки);

Fig. 2. Formation of B. purpuraria embryos: A - fission into 2-4 cells (2-3 days of cultivation); 5 - embryogenic structure with suspensor (7 days of cultivation); B - globular stage of embryoid development (15 days); $\Gamma$ - torpedo development stage of embryo (19 days) 


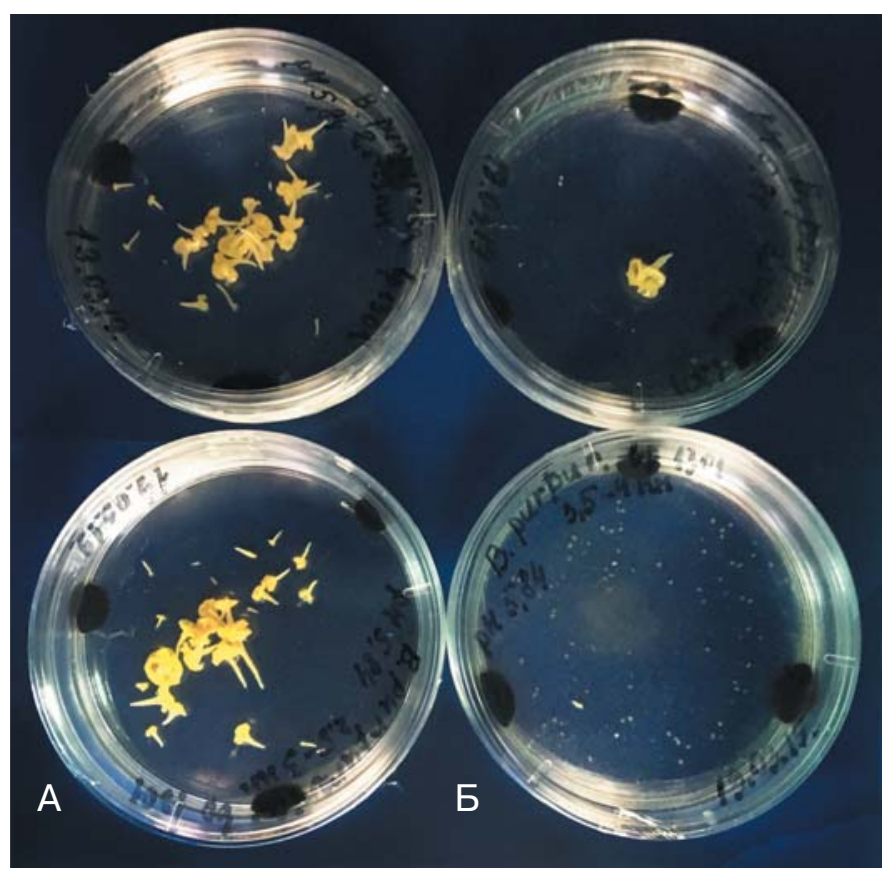

Рис. 3. Выход эмбриоидов В. purpuraria растения №1 сортообразца №1301(Китай) в зависимости от линейного размера бутонов: А - 2.5-3.2 мм; Б - 3.3-4.0 мм

Fig. 3. Yield of embryos of B. purpuraria of plant No. 1 of variety No. 1301 (China) depending on the linear size of buds: A - 2.53. $2 \mathrm{~mm}$; Б - 3.3-4.0 $\mathrm{mm}$

течение первых шести суток.

Для повышения отзывчивости растения №2 сортообразца №1301, был заложен опыт по стимуляции эмбриогенеза путем добавления нитрата серебра в концентрации 0,1 мг/л в состав питательной среды для индукции, что привело к увеличению выхода эмбриоидов в среднем более чем в 2 раза (табл. 4). В результате выход эмбриоидов достигал 12 шт на чашку Петри.

На этапе регенерации эмбриоидов B. purpuraria в культуре микроспор in vitro основной проблемой стало проявление признаков альбинизма у регенерантов на стадии семядольных листьев, у которых отмечали варьирование по интенсивности окраски. Количество зелёных растений составляло от 44\% до 50\%, альбиносных растений - от 42\% до 44\%, с частичным нарушением окраски - от 5\% до 11\%, в зависимости от донорного растения и повторности (рис.4). При этом размер бутонов не влиял на соотношение растений с разной интенсивностью окраски семядольных листьев. При дальнейшем культивировании альбиносные растения погибали.

Растения с нормальным содержанием хлорофилла по мере развития переносили на безгормональную среду МС (pH 5,8) с 2\% сахарозой и 7 г/л агара для укоренения, после чего они проходили адаптацию in vivo в климатической камере (рис. 5).

В результате исследований было получено 38 растенийрегенерантов сортообразца №1301, большая часть из которых была передана селекционерам. Оставшиеся растения были доведены до цветения в условиях климакамеры. У всех растений, за исключением четырех, у которых проявилась самонесовместимость, удалось получить семенное потомство (рис. 6).

Растения с разным габитусом куста были выборочно проверены на плоидность с помощью прямого подсчета хромосом, одно растение оказалось с гаплоидным набором хромосом и вскоре погибло (рис. 7Б, В), все остальные были диплоидными (рис. 7А).

Было установлено, что исследованные образцы, полученные в культуре микроспор in vitro, являются идентичными контрольному донорному растению по содержанию ДНК в ядре (ключевой показатель Mean - среднее пика), следовательно, имеют одинаковую плоидность. Также были получе-
Таблица 4. Выход эмбриоидов В. purpuraria растения №2 сортообразца №1301(Китай)

Table 4. The yield of embryoids of B. purpuraria plant No. 2 variety No. 1301(China)

\begin{tabular}{|c|c|c|}
\hline Повторности & \multicolumn{2}{|c|}{ Состав среды для индукции } \\
\hline & контроль NLN-13 & NLN-13+AgNO \\
\hline 1 & 2 & 10 \\
\hline 2 & 2 & 12 \\
\hline 3 & 3 & 5 \\
\hline среднее & $2.3 \pm 0.4$ & $9 \pm 2.7$ \\
\hline
\end{tabular}

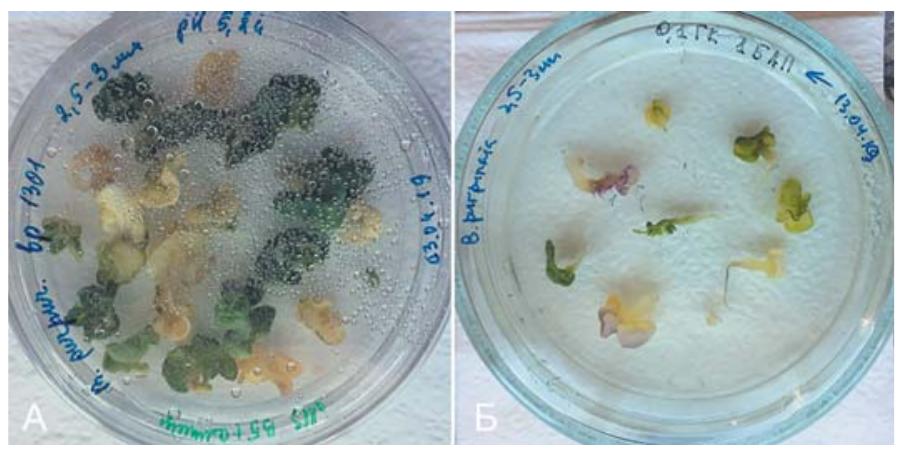

Рис. 4. Эмбриоиды В. purpuraria: A - на регенерационной среде МС (рН 5, 8); Б - на регенерационной среде МС (рН 5, 8) с добавлением регуляторов роста ГК 0, 1 мг/л и БАП 1 мг/л Fig. 4. Embryos of $B$. purpuraria: $A-$ on the regenerative medium MS (pH 5.8); Б - on the regeneration medium MS (pH 5.8) with the addition of growth regulators GC 0.1 $\mathrm{mg} / \mathrm{l}$ and BAP $1 \mathrm{mg} / \mathrm{I}$

ны результаты исследования размера генома (2C) в пикограммах (пг) относительно стандартного образца Ficus benjamina c размером генома $2 \mathrm{C}=1,07$ пг, которые подтвердили (рис. 9), что все исследованные образцы были удвоенными гаплоидами.

\section{Заключение}

В ходе исследований было показано, что отзывчивость к эмбриогенезу в культуре микроспор in vitro у культуры B.purpuraria существенно отличается не только между сортообразцами, но и в пределах каждого из них у отдельных растений. Это может быть связано как с мощностью габитуса растения, так и с его раннеспелостью, то есть скоростью вступления в фазу стеблевания и цветения. Установлены оптимальные линейные размеры бутонов (2,5-3,2 мм) с максимальным содержанием одноядерных вакуолизированных микроспор на поздней стадии развития и ранней двуядерной пыльцы, которые наиболее восприимчивы к эмбриогенезу. Положительное влияние на индукцию эмбриогенеза так же оказывает добавление в индукционную среду нитрата серебра, повышая выход эмбриоидов в два и более раз.

Показано, что одной из основных проблем получения DHрастений на этапе регенерации у B. purpuraria является альбинизм - около 50\% всех растений-регенератов оказались альбиносами в разной степени и были не жизнеспособны. Было выявлено, что для культуры B. purpuraria вынужденная полиплоидизация не требуется, поскольку почти у всех растений, успешно прошедших этап адаптации к условиям in vivo, произошло спонтанное удвоение хромосом. Проблемой получения семенного потомства удвоенных гаплоидов является самонесовместимость, которую можно иногда преодолеть опылением своей пыльцой в бутонах.

В результате проведенной работы нам удалось получить в культуре микроспор in vitro DH-растения капусты пурпурной и семенное потомство некоторых их них. Полученный материал передан селекционерам. 


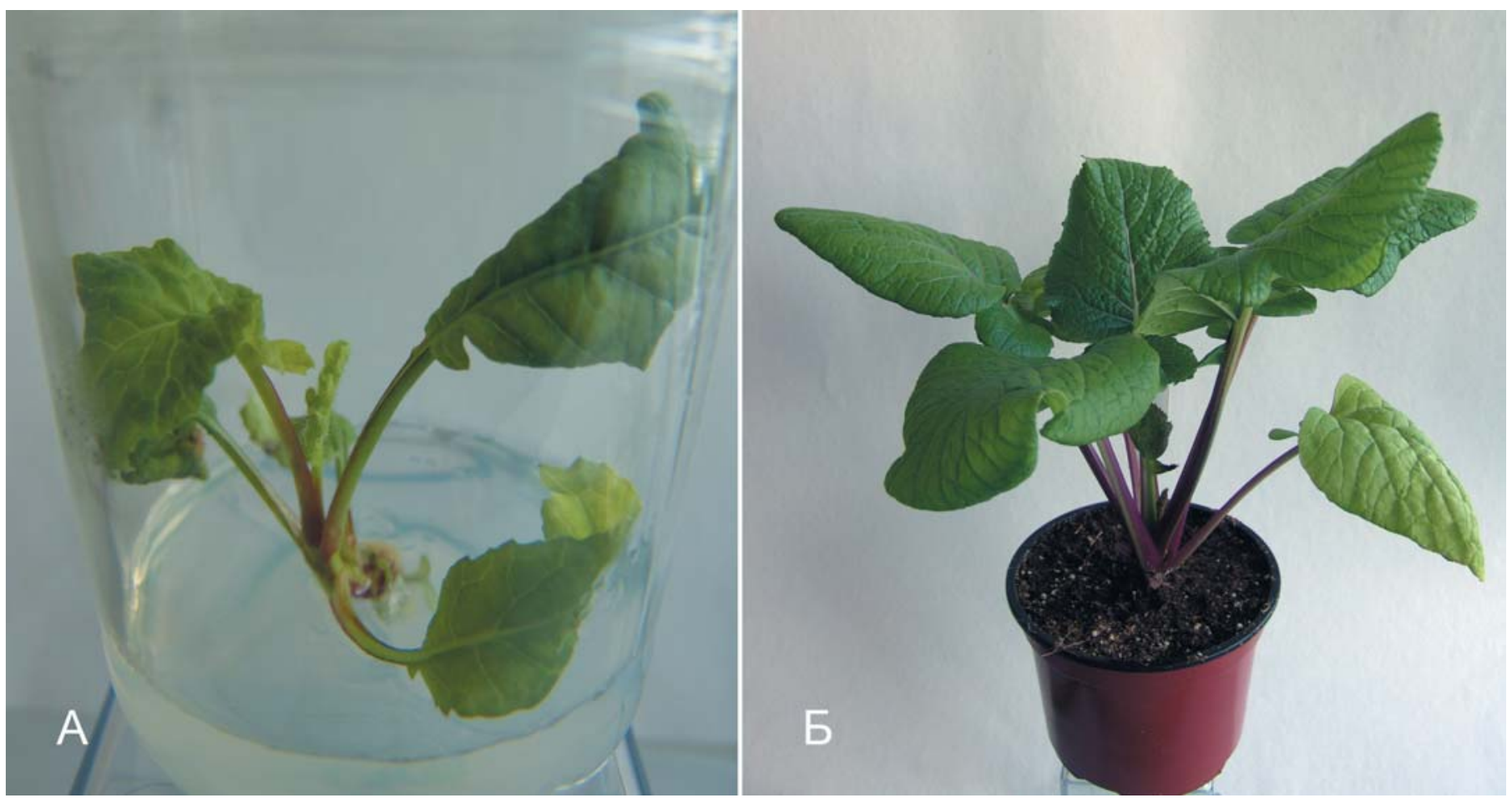

Рис. 5. Укоренение и адаптация растений-регенерантов В.рurpuraria:

A - in vitro на безгормональной среде МС; Б - in vivo в почвенном субстрате

Fig. 5. Rooting and adaptation of $B$. purpuraria regenerated plants:

$A$ - in vitro on hormone-free MS medium; 5 - in vivo in soil substrate
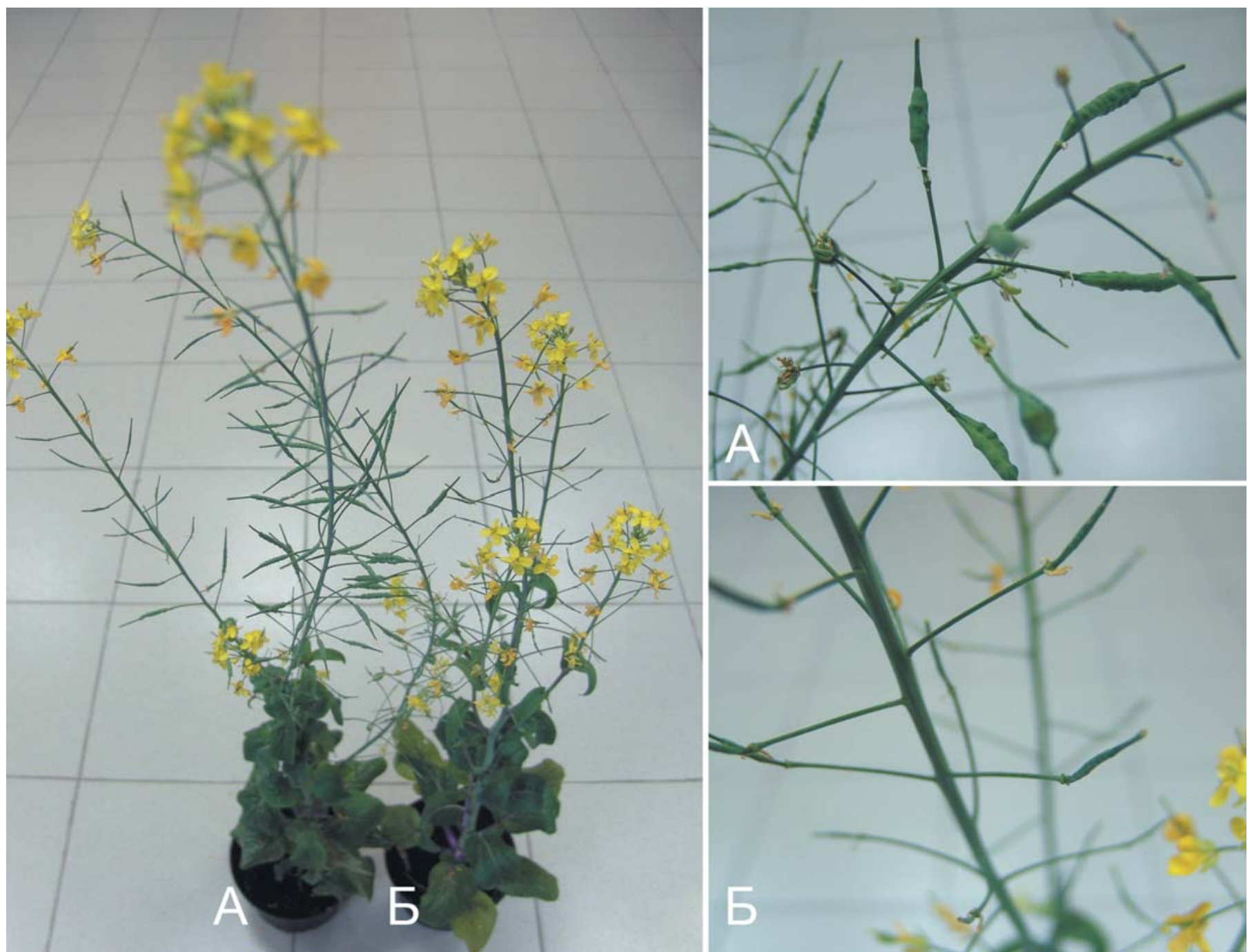

Рис. 6. Растения В. purpuraria: A - самосовместимое; Б-самонесовместимое

Fig. 6. Plants B. purpuraria: A - self-compatible; 5 - self-incompatible 


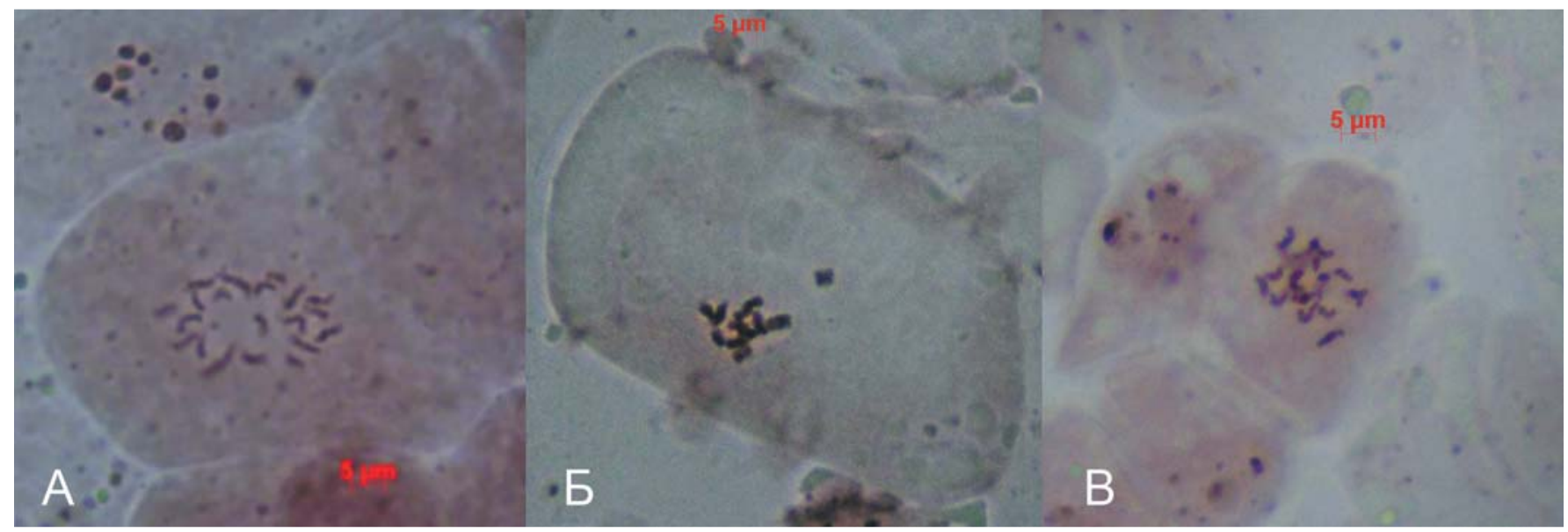

Рис. 7. Растения В. purpuraria: A - диплоидное растение $2 n=20,5$ - гаплоидное растение,

$n=10$; $B$ - гаплоидное растение, $n=10$, ранняя анафаза

Fig. 7. Plants of B. purpuraria: A-diploid plant $2 n=20,5$ - haploid plant, $n=10 ; B$ - haploid plant, $n=10$, early anaphase
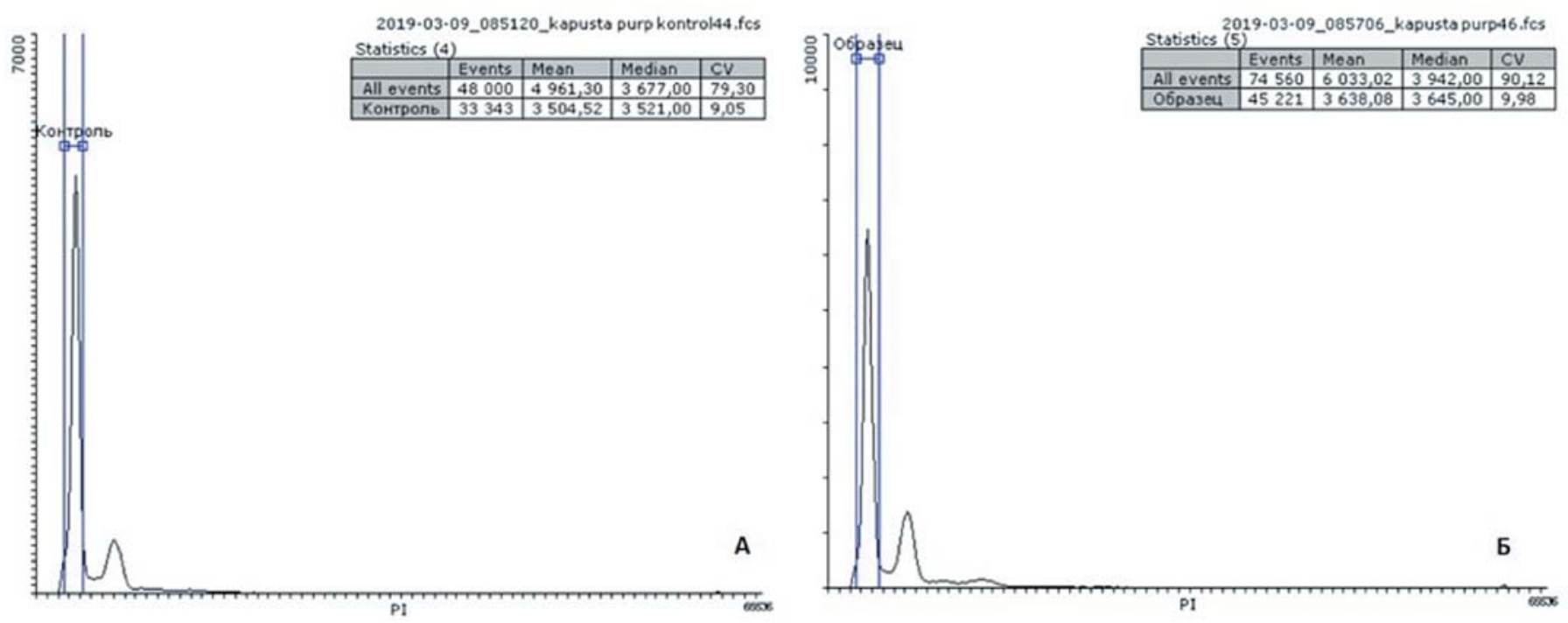

Рис. 8. Гистограммы образцов В. purpuraria: A - донорное растение, Б - DН-растение

Fig. 8. Histograms of B. purpuraria varieties: A - donor plant, $\bar{B}-\mathrm{DH}$-plant

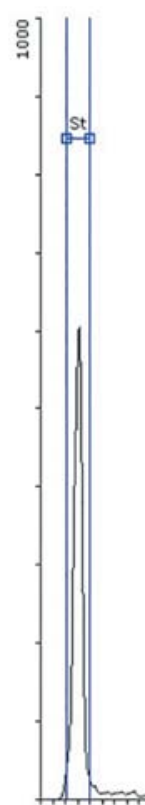

\begin{tabular}{|l|r|r|r|r|}
\hline \multicolumn{4}{|c|}{ Events } & \multicolumn{2}{c|}{ Mean } & Median & CV \\
\hline All events_113109_ficus380.fcs \\
\hline St & 4224 & 3565,71 & 3103 & 86,3 \\
\hline
\end{tabular}
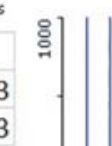

2019-03-11_114005_purp43 380.fcs

\begin{tabular}{|l|r|l|r|r|}
\hline & Events & Mean & Median & CV \\
\hline All events & 4960 & 4270,72 & 3054 & 83,6 \\
\hline Sm & 3306 & 2907,62 & 2924 & 11,1 \\
\hline
\end{tabular}

A

Рис. 9. Гистограммы образцов: A - F. benjamina, Б - В. purpuraria

Fig. 9. The histogram of the varieties: $A-F$. benjamina, $\bar{B}-B$. purpuraria 


\section{Об авторах:}

Козарь Елена Викторовна - м.н.С. лаб. репродуктивной биотехнологии в селекции с.-х. растений, https://orcid.org/0000-0002-1319-5631

Коротцева Ксения Святославовна - М.н.С. лаб. репродуктивной биотехнологии в селекции с.-х. растений, https://orcid.org/0000-0002-2284-0532 Романова Ольга Витальевна - кандидат с.-х. наук, м.н.с. лаб. репродуктивной биотехнологии в селекции с.-х. растений, https://orcid.org/0000-

0002-6513-1541

Чичварина Ольга Александровна - М.н.с. лаб. репродуктивной биотехнологии в селекции с.-х. растений, https://orcid.org/0000-0001-5297-2969

Кан Людмила Юрьевна - кандидат с.-х. наук,

с.н.с. лаб. генетики и цитологии, https://orcid.org/0000-0001-7902-503X

Ахраменко Владислав Анатольевич - м.н.с. лаб. репродуктивной биотехнологии в селекции с.-х. растений

Домблидес Елена Алексеевна - кандидат с.-х. наук,

зав. лаб. репродуктивной биотехнологии в селекции с.-х. растений, https://orcid.org/0000-0002-2695-190X

\section{About the authors:}

Elena V. Kozar - Junior Researcher of Laboratory of Reproductive Biotechnology in Crop Breeding, https://orcid.org/0000-0002-1319-5631 Ksenia S. Korottseva - Junior Researcher of Laboratory of Reproductive Biotechnology in Crop Breeding, https://orcid.org/0000-0002-2284-0532 OIga V. Romanova - Cand. Sci. (Agriculture), Junior Researcher of Laboratory of Reproductive Biotechnology in Crop Breeding, https://orcid.org/0000-0002-6513-1541

Olga A. Chichvarina - Junior Researcher of Laboratory of Reproductive Biotechnology in Crop Breeding, https://orcid.org/0000-0001-5297-2969 Lyudmila Yu. Kan - Ph.D. in Agriculture, Senior Researcher, Laboratory of Genetics and Cytology, https://orcid.org/0000-0001-7902-503X

Vladislav A. Ahramenko - Junior Researcher of Laboratory of Reproductive Biotechnology in Crop Breeding

Elena A. Domblides - Cand. Sci. (Agriculture), Head of Laboratory of Reproductive Biotechnology in Crop Breeding, https://orcid.org/0000-00022695-190X

24. Murashige T, Skoog F. A revised medium for rapid growth and bioassays with tobacco cultures. Physiologia Plantarum, 1962;15:473-497.

25. Na H., Kwak J.H., Chun C. The effect of plant growth regulators, activated charcoal and $\mathrm{AgNO}_{3}$ on microspore derived embryo formation in broccoli (Brassica oleracea L. var. italica). Hort. Environ. Biotechnol. 2011;52(5):524 529. https://doi.org/10.1007/s13580-011-0034-7

26. Pechan PM, Keller WA. Identification of potentially embryogenic microspores in Brassica napus. Physiol. Plant. 1988;74:377-384.

27. Smith HB. Photosynthetic pigmentation-variegations on a theme. Plant Cell. 1999;11:1-14

28. Wang $\mathrm{C}$, Li H, Li Y. Genetic characterization and fine mapping BrCER4 in involved cuticular wax formation in purple cai-tai (Brassica rapa L. var. purpurea) Mol Breeding. 2019;39:12. https://doi.org/10.1007/s11032-018-0919-6

29. Wang T, Li HX, Zhang J. Initiation and development of microspore embryogenesis in recalcitrant purple flowering stalk (Brassica campestris ssp. chinensis var. purpurea Hort.) genotypes. Scientia Horticulturae. 2009;121(4):419-424.

30. Wang TT, Li HX, Zhang JH et al. Isolated microspore culture and plant regeneration in purple flowering stalk (Brassica campestris ssp. chinensis var. purpurea Hort.). J. Wuhan Botanical Research. 2004;22(6):569-5712004

31. Wang $Y, H e ~ Y$, Yang $M$ et al. Fine mapping of a dominant gene conferring chlorophyll- deficiency in Brassica napus. Scientific Reports. 2016;6:31419.

32. Wuhan Bot. Res. 22: $569-571$ (in Chinese with English summary).Biddington NL, Sutherland RA and Robinson HT. Silver nitrate increases embryo production in anther culture of Brussels sprouts. Ann. Bot. 1988;62:181-185.

33. Вюртц Т.С., Домблидес Е.А., Шмыкова Н.А., Федорова М.И., Кан Л.Ю. Домблидес А.С.. Получение DH-растений в культуре микроспор моркови. Овощи России. 2017;(5):25-30. https://doi.org/10.18619/2072-9146-20175-25-30 [Vjurtts T.S., Domblides E.A., Shmykova N.A., Fedorova M.I., Kan L.J. Domblides A.S. Production of $\mathrm{DH}$-plants in culture of isolated microspore in carrot. Vegetable crops of Russia. 2017;(5):25-30. (In Russ.) https://doi.org/10.18619/2072-9146-2017-5-25-30]

34. Домблидес Е.А. и др. Технология получения удвоенных гаплоидов в культуре микроспор семейства капустные (методические рекомендации). Коллектив авторов. ВНИИССОК. М.: Изд-во ВНИИССОК. 2016. [Domblides E.A. et al. Technology for development doubled haploids of cabbage in microspores culture (methodical recommendations). Team of authors. Moscow: VNIISSOK publishing House. 2016. (In Russ.)]

35. Козарь Е.В., Домблидес Е.А., Солдатенко А.В. Получение удвоенных гаплоидов редиса в культуре микроспор in vitro. Биотехнология в растениеводстве, животноводстве и ветеринарии. 2018:123-125. [Kozar E.V. Domblides E.A., Soldatenko A.V. Development of radish doubled haploids in microspore culture in vitro. Biotechnology in crop production, animal husbandry and veterinary medicine. 2018:123-125. (In Russ.)]

36. Козарь Е.Г. Биологическая активность вторичных метаболитов растений семейства Brassicaceae. Овощи России. 2011;1(10):46-53. [Kozar E.G. Biological activity of secondary metabolite in plants of Brassicaceae family. Vegetables crops of Russia. 2011:1(10):46-53. (In Russ.)]

37. Козарь Е.Г., Кононков П.Ф., Гинс М.С., Байков А.А., Шестеперов А.А. Биологическая и антиоксидантная активность водяного кресса. Новые и нетрадиц. растения и перспективы их использования. Общерос. акад нетрадиц. и редких растений (и др.). Москва. 2017:04-112. [Kozar E.G. Kononkov P.F., Gins M.S., Baykov A.A., Shesteperov A.A. Biological and antioxidant activity of watercress. New and non-traditional plants and prospects of their use. All Russian Acad. non-traditional and rare plants (etc.). Moscow. 2017:04-112. (In Russ.)]

38. Скапцов М.В., Смирнов С.В., Куцев М.Г., Шмаков А.И. Проблемы стандартизации В проточной цитометрии растений. Turczaninowia. 2016;19(3):120-122. [Skaptsov M.V., Smirnov S.V., Kutsev M.G., Shmakov A.I. Problems of a standardization in plant flow cytometry. Turczaninowia. 2016,19(3):120-122. https://doi.org/ 10.14258/turczaninowia.19.3.9. (In Russ.)] 